\title{
Mensaje del presidente de la Asociación Mexicana de Cirugía Endoscópica
}

\author{
Message from the president of the Mexican Association of Endoscopic Surgery \\ Jorge Fernando Ugalde Velásquez* \\ * Presidente de la Asociación Mexicana de Cirugía Endoscópica, 2021-2022.
}

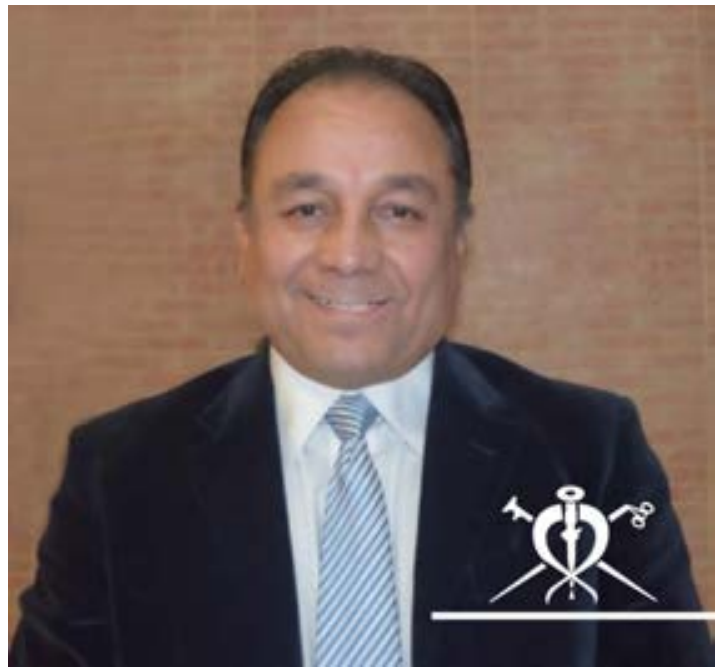

Es para mí motivo de orgullo y un honor presidir nuestra Asociación. Agradezco el apoyo y participación de todos ustedes en nuestras actividades.

Como todos sabemos, la función de la Asociación Mexicana de Cirugía Endoscópica (AMCE) seguirá siendo el promover y apoyar el progreso de la cirugía en México y el crecimiento teórico y práctico de los cirujanos del país.
Contamos con la participación y apoyo de un gran número de prestigiosos cirujanos de México y de diferentes lugares del mundo, quienes se encuentran trabajando con nosotros en diferentes actividades que ya iniciamos y mantendremos durante la gestión para culminar con el XXX Congreso Internacional de Cirugía Endoscópica, el cual Ilevaremos a cabo en Puerto Vallarta del 3 al 7 de mayo de 2022.

La actual Mesa Directiva y el Comité Científico, junto a destacados cirujanos, nos encontramos preparando un ambicioso programa científico que, estamos seguros, cumplirá las expectativas de todos los cirujanos.

Tenemos el compromiso de asociaciones y grupos nacionales y extranjeros de gran nivel en cirugía de mínima invasión que contribuirán a lograr que éste sea un gran evento.

Continuaremos con la publicación periódica de nuestra revista, la cual tiene una reproducción importante por diferentes especialidades médicas a nivel global y por los diferentes medios de difusión que actualmente son de mayor utilización. De este modo, la información, actualización y renovación de nuevas y mejores tecnologías estarán al alcance de los cirujanos que lo requieran.

Actualmente, se ha modernizado la plataforma de la casa editorial Medigraphic, lo que hace que la publicación de artículos en las versiones impresa y electrónica sea más 
amigable y fácil de realizar. Todos están invitados a publicar sus experiencias.

El mundo atraviesa una emergencia de salud sin precedentes. A pesar de ello, la AMCE ha mantenido su labor académica asistencial y, actualmente, pretendemos incrementarla de manera progresiva en la medida que las condiciones sanitarias lo permitan.

Como ya mencionamos en diferentes foros, acompañamos en su dolor a las familias que sufrieron la pérdida de alguien a causa de la pandemia y en especial lamentamos la pérdida de socios y/o familiares fallecidos durante este tiempo.
Esperamos que las actividades que ya emprendimos sirvan para lograr lo que los cirujanos buscamos siempre: el desarrollo profesional personal y de la cirugía en general.

Para la AMCE, la participación de sus miembros en nuestras actividades es el motor que nos mueve a seguir creciendo. Es una obligación nuestra cumplir y superar sus expectativas.

Gracias a todos por seguir con nosotros. 